Journal of the Egyptian Society of Parasitology, Vol.43, No.3, December 2013 J. Egypt. Soc. Parasitol., 43(3), 2013: 601 - 608

\title{
THE INFANTILE VISCERAL LEISHMANIASIS: \\ COULD IT ATTACK EGYPTIAN NORTH COASTAL REGION AGAIN?
}

By

MAMDOUH M. EL-BAHNASAWY ${ }^{1}$, GABR M. SAYED AHMED ${ }^{2}$

WAFAA ALY I. GABER ${ }^{3}$ AND TOSSON A. MORSY ${ }^{4}$

Military Medical Academy ${ }^{1}$, Department of Public Health and Hygiene,

Faculty of Medicine, Al-Azhar University ${ }^{2}$, Head of Nurses, Alexandria Armed Forces Hospital ${ }^{3}$ and Department of Parasitology, Faculty of Medicine, Ain Shams University, Cairo $11566^{4}$, Egypt

\begin{abstract}
Visceral leishmaniasis is caused by three species of the $L$. donovani complex: $L$. donovani, L. infantum, and L. chagasi. Infections with these organisms are often asymptomatic or very mild, but in a minority of individuals there is progression to severe symptomatic disease. This is associated with spread of the infection throughout the reticuloendothelial system. L. infantum typically affect children below the age of 5 years. However, IVL can also occur in immunosuppressed adults, such as transplant recipients and patients receiving immunosuppressive chemotherapy or patients suffering from chronic intestinal schistosomiasis.

IVL was encountered in Al-Agamy, Alexandria on 1983 with Phlebotomus langeroni. This vector is still abundant with low density away from Al-Agamy. Urbanization of the north coastal area in the vicinity of Alexandria changes the ecological status but how does it affect the behavior of sandflies; mainly the IVL vector Phlebotomus langeroni? Many employees and their families return home from Libya with fever with or without other accompanying symptoms. Fever can be a manifestation of a minor, self-limited process or can herald a progressive, lifethreatening illness.

The detection of Phlebotomus langeroni in El-Hamam City, Sedi Barany City, and Matrooh City and the abundance $P$. papatasii in these three cities in addition to Al Agamy must be taken into consideration of the Public Health Authority.

Key Words: Egypt, Infantile visceral leishmaniasis, Sandflies, Re-emerging?

\section{Introduction}

There is a long history of visceral leishmaniasis from Alexandria, Egypt (Panayotatou, 1922), Hassan (1968) reported a case of Kala-azar. However, the disease impact on human health in

El Agamy, Alexandria was not really recognized until 1982 (Tewfik et al, 1983). Mansour et al. (1984) in Al Agamy characterized the Leishmania isolates from children with infantile visceral leishmaniasis. Soliman et al. (1984) experimental found that the
\end{abstract}


Pentostam the drug of choice in the treatment of visceral leishmaniasis in Egypt had side effects mainly on the liver. On the other hand, Phlebotomus langeroni was the proven vector of infantile visceral leishmaniasis in El Agamy as it meets all the established criteria for the vectorial competence, essentially its anthropophily and the feeding on the reservoir host (Morsy et al, 1983; El Sawaf et al, 1989), spatial distribution coincided with the human cases (Beier et al, 1986), natural infection by Leishmania infantum (Doha and Shehata, 1992) and transmission of disease by bite (El Sawaf et al, 2012).

El Sawaf et al. (2008) experimentally L. infantum and L. major in the midgut of infected $P$. langeroni and $P$. papatasi showed difference in flagella mode of attachment to the midgut of their respective sand fly vectors suggested higher adaptation between $L$. major $/ P$. papatasi compared to $L$. infantum $/ P$. langeroni.

Kassem et al. (2012) stated that the epidemiological significance of P. lan- geroni highlighted the importance of entomological surveillance and monitoring measures, especially considering its displacement or migration, allowing the maintenance of the visceral leishmaniasis transmission cycle in the rural environment.

The present objective aimed at the surveying of selected areas in the North Coastal Zone for Phlebotomus langeroni, the main vector of the previous documented infantile visceral leishmaniasis in the vicinity of Al-Agamy, Alexandria.

\section{Materials and Methods}

The sticky paper traps $(\mathrm{N}=100)$ coated with castor oil, were set up randomly around houses $2 \mathrm{hr}$. before sunset and were collected the next early morning (Morsy et al, 1989). Twenty-five standard sticky traps were distributed in each of Abo-Talaat north of Al-Agamy, El-Hamam City, Sedi-Barany City and Matrooh City. The keys given by Morsy et al. (1990) and Lane (1993) were adopted for the identification of the collected sandflies in these surveys.

\section{Result}

Table 1: Identified sandflies in the different sites

\begin{tabular}{|l|c|c|}
\hline Site & Phlebotomus papatasii & Phlebotomus langeroni \\
\hline Abo-Talaat & ++ & - \\
\hline El-Hamam City & ++ & + \\
\hline Sedi Barany City & ++ & + \\
\hline Matrooh City & ++ & ++ \\
\hline
\end{tabular}

$+=$ one female/trap/night

In the present study, the ZCL vector; $P$. papatasii was common abundantly in the four examined sites. On the other hand, the IVL vector; Plebotomus langeroni was trapped from three sites; in a descending order of abundance these were El-Hamam City, Sedi-Barany City and Matrooh City, but not from AlAgamy vicinity where it was previously abundant and many proven clinical and parasitological infantile visceral leishmaniasis cases in the 1980s. 


\section{Discussion}

El Okby et al. (1989) in Al Agamy over two successive years found a bimodel or two peaks a year for P. papatasi and $P$. langeroni. The blood of $P$. papatasi females was mainly human blood, while that of $P$. langeroni ones was mainly non-human blood. El Sawaf et al. (1989) examined blood meals from 602 P. papatasi and $49 P$. langeroni in El Agamy. Of 597 P. papatasi collected indoors, 594 contained human blood and three had mixed blood meals (human-dog, human-rat, and human-avian). Four of five $P$. papatasi collected outdoors contained human blood and one contained avian blood. All 39 P. langeroni collected indoors had fed on humans. Six of 10 outdoorcollected P. langeroni had fed on human blood, 2 on dog, 1 on cat, and 1 on rat blood. They concluded that feeding on humans and $\operatorname{dogs}$ by $P$. langeroni supports the role of this species visceral leishmaniasis at the El Agamy focus. Kassem et al. (2012) expected that urbanization has led to the $P$. langeroni displacement to flourish in suitable rural habitats, similar to that previously found in El Agamy.

Cases of feline leishmaniasis have been reported in different countries. Morsy et al. (1980) in Jordan parasitological incriminated stray cats as reservoir hosts visceral leishmaniasis. In Egypt, Michael et al. (1982) and Morsy et al. (1993) reported anti-leishmanial antibodies in street cats in Ismailia and Cairo Governorates respectively. Trainor et al. (2010) in Texas in 5 of 8 cats, L. mexicana DNA was amplified from paraffin-embedded tissue by PCR and sequenced. da Silva et al. (2010) in urban endemic areas in Brazil suggested domestic cats as possible alternative reservoirs of Leishmania (L.) infantum, the causal agent of visceral leishmaniasis (IVL). They reported Lutzomyia longipalpis infected by $L$. infantum from a naturally infected cat by xenodiagnosis. Also, Cadia et al. (2013) in Brazil found specific anti-Toxoplasma IgG in 63 of $386(16.3 \%)$ cats and $\mathrm{IgG}$ against Leishmania spp. in two cats' serum samples. Apart from cats, Morsy et al. (1987) reported Leishmania antibodies in the Egyptian bats.

Morsy et al. (1993) studied the seasonal abundance, nocturnal activity and breeding sites as well as other relevant behavior P. paptasi (Scopoli) the proven vector of zoonotic cutaneous leishmaniasis. They showed that: (a) the seasonal activity started in April and ended in November or beginning of December. (b) Female outnumbered male indoors (7.4:1) and vise-versa outdoors $(0.14: 1)$. (c) Blood fed females were $97.7 \%$ indoors and $29.4 \%$ outdoors. (d) The nocturnal activity ranged between 6 p.m. to 6 a.m. indoors and 8 p.m. to 6 a.m. outdoors. (e) the immature stages of Phlebotomus were successfully recovered from rodent burrows and poultry sheds.

Abdel Badei et al. (2012) studied the morphometrics and protein composition of salivary glands of colonised $P$. papatasi and $P$. langeroni sand flies from Egypt. Female glands were dissected at day 1 (D1, unfed), day 2 (D2, sugar-fed), day 3 (D3, blood-fed) and day 7 (D7, blood-digested). P. papatasi 
had larger lobes and higher protein content than P. langeroni ones. P. papatasi $\mathrm{D} 1$ flies had 15 protein bands that decreased in the D2, D3 and D7 flies to 10 bands in the Sinai flies and 9 bands in the Alexandria flies. All $P$. langeroni flies had 12 protein bands but with different intensities. The results reveal inter-specific variation between $P$. papatasi and $P$. langeroni, while no intra-specific variation between $P$. papatasi strains.

Abroad, Chelbi and Zhioua (2007) experimentally found that the Tunisian strain of $P$. papatasi could reproduce autogenously or anautogenously, depen-ding on the availability of a suitable blood-meal source. Chelbi et al. (2008) reported that $P$. papatasi proved to be zoo-prophylaxis. The indoor abundance of $P$. papatasi in houses with rabbit holes in the peri-domestic areas was significantly lower than the indoor abundance in houses without rabbit holes in their peridomestic areas. They strongly suggested that zoo-prophylaxis could be effective in reducing the indoor abundance of $P$. papatasi and subsequently might be used to control the transmission L. major in rural areas. Derbali et al. (2012) studied the ability of $P$. papatasi to transmit $L$. major under laboratory conditions. The sand flies became infected with L. major after feeding on a lesion of needleinoculated Meriones shawi. Previously infected $P$. papatasi trans-mitted $L$. major to $M$. shawi by bite during a second blood-meal. Two months after the blood-meal, the animal developed a lesion on its ears. The infectivity of $M$. shawi to $P$. papatasi lasted for five months, period corresponding to winter season in North Africa. They concluded that reservoir hosts surviving winter time are the main source of infection for $P$. papatasi during the following season, and subsequently they play a major role in the persistence and transmission of $L$. major between transmission cycles.

As to the reservoir host; Morsy et al. (1983) reported ELISA and IHAT antileishmanial antibodies in street and pet in the vicinity of Al-Agamy. Morsy et al. (1987) in Al-Agamy typed two leishmanial isolates from dogs serologically and biochemically as L. major. This was the second time that $L$. major has been shown to occur in dogs in Saudi Arabia by Elbihari et al. (1987) who suggested that dogs were probably victims rather than reservoirs of Leishmania. Morsy et al. (1988) in AlAgamy isolated a flagellate parasite from the spleens of two $R$. norvegicus typed serologically by excreted factor serotyping and enzymological by thick starch electrophoresis of four of its enzymes: GPI, G6PD, 6PGD and PGM. The same type of parasite was isolated from two stray dogs from the same vicinity. This flagellate was quite distinct from Leishmania donovani, L. major and L. tropica, the three common Old World species of Leishmania; but its exact identity remains uncertain. They concluded that it could be a new leishmanial entity or a flagellate parasite of another genus.

Nowadays, the visceral leishmaniasis (VL) is documented in Egypt mainly in Al Agamy, Alexandria. Other studies all over Egypt (based on the clinical 
and/or serological diagnosis rather than demonstration of the parasites) raised the possibility of adult affection with visceral leishmaniasis. The point is that visceral leishmaniasis, shares many clinical manifestations with other diseases known in Egypt as schistosomiasis mansoni, hepatic amoebiasis, toxoplasmosis, and malaria (Morsy, 1997). Besides, Feinsod et al. (1988) in a focus of IVL in Al Agamy, found adults by radioimmune assay to have leishmanial antibodies. Ten of 16 seropositive individuals were on corticosteroids compared to one of 22 seronegative ones $(\mathrm{P}=0.0002)$. Two seropositive individuals (a woman and a man) were taking phenylbutazone, and two women were taking female sex hormones. The association between immunosuppressive medication and leishmanial seropositivity suggested that acquired changes in host population immunocompetence might significantly alter age-specific seroprevalence of leishmanial antibodies. Soliman (1992) in ElMax area west of Alexandria reported $6.2 \%$ IFAT positivity among 96 pupils.

Apart from Al Agamy, Alexandria, Madwar et al. (1985) suggested the possibility of VL in Qalyoubia Governorate. A case of infantile visceral leishmaniasis was identified in an adult farmer (unusual host) in Qalyoubia District the patient suffered from hepato-splenomegaly and who never left his home area (Kabil et al, 1988).

El Mahdy et al. (1993) in Dakahlia reported Leishmania-positive by IHAT and dot-ELISA in 4/22 hypersplenic patients with Leishmania amastigotes were demonstrated in splenic smears of two patients obtained during splenectomy. One culture grew promastigotes. Morsy et al. (1993) in Abo Hamad, Sharkia reported lymphatic leishmaniasis as an indigenous infection in a 30 year old male. Cervical lymphadenopathy was the only clinical sign but no visceral involvement. The patient was successfully treated with sodium stibogluconate as shown clinically and parasitologically. They stated that lymphatic leishma- niasis should be in mind when dealing- with lymphanopathy of unknown etiology. Again, Rosypal et al. (2013) examined blood samples from 50 stray dogs in Giza for antibodies to visceralizing Leishmania spp. by commercial immunochromatographic strip assays based on recombinant antigen K39. The antibodies to Leishmania spp. were found in 5 of 50 $(10 \%)$ of dogs tested from Egypt. They stated that the stray dogs are exposed to the visceralizing Leishmania species in Egypt.

\section{Conclusion}

Generally speaking, with rapid international travel, it is very common to diagnose infectious diseases in areas where they were not known before.

Besides, leishmaniasis is an insectborne zoonotic disease with a worldwide distribution. Leishmania spp. infections cause a broad spectrum of the clinical signs, ranging from skin lesions to fatal visceral disease. The dogs are a major reservoir host for visceral leishmaniasis.

The presence of Phlebotomus langeroni in some sites west to Al Agamy and the endemicity of infantile visceral 
leishmanisis in Libya very near to the Libyan-Egyptian board as well as travelers returning home must be in consideration.

Besides, one must take into consideration the serologic and parasitological detection of natural leishmanial infection in pet and street cats and signify their role and perhaps other carnivores in the epidemiology of disease; leishmaniasis public awareness of its complications and the importance of early detection could affect its prognosis.

\section{References}

Abdel-Badei, NM, Khater, EI, Daba, S, Shehata, MG, 2012: Morphometrics and protein profiles of the salivary glands of Phlebotomus papatasi and Phlebotomus langeroni sand flies: outbreak of infantile kala-azar in the area of Alexandria is discussed. Trans. R. Soc. Trop. Med. Hyg. 106, 4:235-42.

Beier, JC, El Sawaf, BM, Merdan, A I, El Said, S, 1986: Sand flies (Diptera: Psychodidae) associated with visceral leishmaniasis in El Agamy, Alexandria Governorate, Egypt. I. Population ecology. J. Med. Entomol. 23:600 -8 .

Cardia, DF, Camossi, LG, Neto, LD, Langoni, H, Bresciani, KD, 2013: Prevalence of Toxoplasma gondii and Leishmania spp. infection in cats from Brazil. Vet. Parasitol. 2013 Jul 20. pii: S0304-4017(13)00391-9. [Epub ahead of print].

Chelbi, I, Zhioua, E, 2007: Biology of Phlebotomus papatasi (Diptera: Psychodidae) in the laboratory. J. Med. Entomol. 44, 4:597-600
Chelbi, I, Kaabi, B, Derbali, M, Ahmed, SB, Dellagi, K, et al, 2008: Zooprophylaxis: impact of breeding rabbits around houses on reducing the indoor abundance of Phlebotomus papatasi. Vector Borne Zoonotic Dis. 8, 6:741-7.

da Silva, SM, Rabelo, PF, Gontijo Nde, F, Ribeiro, RR, Melo, MN, et al, 2010: First report of infection of Lutzomyia longipalpis by Leishmania (Leishmania) infantum from a naturally infected cat of Brazil. Vet. Parasitol. 174, 1/2:150-4

Derbali, M, Chelbi, I, Ben Hadj Ahmed, S, Zhioua, E, 2012: Leishmania major Yakimoff et Schokhor, 1914 (Kinetoplastida: Trypanosomatidae) in Meriones shawi Duvernoy, 1842 (Rodentia: Gerbillidae): persistence of the infection in meriones and its infectivity for the sand fly vector (Phlebotomus) papatasi Scopoli, 1786 (Diptera: Psychodidae). Bull. Soc. Pathol. Exot. 105, 5:399-402

Doha, S, Shehata, MG, 1992: Leishmania infantum MON-98 isolated from naturally infected Phlebotomus langeroni (Diptera: Psychodidae) in El Agamy, Egypt. J. Med. Entomol. 29:891-3.

Doha, S, Shehata, MG, EI Said, S, El Sawaf, BM, 1991: Dispersal of Phlebotomus papatasi (Scopoli) and Phlebotomus langeroni Nitzulescu in El Hammam Matrouh Egypt. Ann. Parsitol. Hum. Comp. 2:69-76.

Elbihari, S, Cheema, AH, el-Hassan, AM, 1987: Leishmania infecting man and wild animals in Saudi Arabia. 4. Canine cutaneous leishmaniasis in the Eastern Province. Trans. R. Soc. Trop. Med. Hyg. 81, 6:925-7. 
El Mahdy, A, Morsy, TA, Youssef, M S, el Shazly, AM, Hammoda, NE, 1993: Visceral leishmaniasis among hypersplenic patients in Dakahlia Governorate, Egypt. J. Egypt. Soc. Parasitol. 23, 2:563-77.

El Okbi, LM, Morsy, TA, Khalid, M L, Salama, MM, Bebars, MA, et al, 1989: Some aspects of sandflies of the genus Phlebotomus in El Agamy, Alexandria. J. Egypt. Soc. Parasitol. 19, 2: 437-46.

EI Sawaf, BM, Mansour, NS, EI Said, SM, Daba, S, Youssef, FG, et al, 1989: Feeding patterns of Phlebotomus papatasi and Phlebotomus langeroni (Diptera: Psychodidae) in El Agamy, Egypt. J. Med. Entomol. 29:497-8.

El Sawaf, BM, Doha, SA, Kamel, K E, Emam, MI, 2008: Attachment of Leishmania major and Leishmania infantum in the midgut of their respective sand fly vectors Phlebotomus papatasi and Phlebotomus langeroni (Diptera: Psychodidae). J. Egypt. Soc. Parasitol. 38, 3:833-42.

El Sawaf, BM, Doha, SA, Imam, MI, 2012: Transmission of Leishmania infantum MON-98 to hamsters by the bite of Phlebotomus langeroni (Diptera: Psychodidae) in El Agamy, Egypt. Acta Trop. 121:44-6.

El Sawaf, BM, Doha, SA, Kamel, K E, Emam, MI, 2008: Attachment of Leishmania major and Leishmania infantum in the midgut of their respective sand fly vectors Phlebotomus papatasi and Phlebotomus langeroni (Diptera: Psychodidae). J. Egypt. Soc. Parasitol. 38, 3:833-4.

Feinsod, FM, Saah, AJ, Faris, RH, el
Said, SM, Karim, NA, et al, 1988: Immunosuppressive medication associated with leishmanial antibodies in adults residing in an endemic focus of infantile visceral leishmaniasis-a case/ control study. Ann. Trop. Med. Parasitol. 82, 5:457-60.

Hassan A, 1968: Kala-azar in Egypt: A case report. J. Egypt. Publ. Hlth. Assoc. 43:S141-5

Kabil, SM, Morsy, TA, Yousef, SM, Lashin, AH, 1988: Leishmania d. infantum from the spleen of an adult patient with hepatosplenomegaly. J. Egypt. Soc. Parasitol. 18, 2:711-5.

Kassem, HA, El Nogoumy, NN, El Sawaf, BM, 2012: Impact of urbanization on the sand fly Phlebotomus langeroni Nitzulescu in an old focus of visceral leishmaniasis in Egypt. J. Egypt. Soc. Parasitol. 42, 3:619-24

Lane, RP, 1993: Sandflies (Phlebotominae) Medical Insects and Arachnids. Springer.com.

Madwar, MA, Morsy, TA, Kabil, S M, Yones, YM, 1985: The possibility of visceral leishmaniasis in Qalyobia Governorate, Egypt. J. Egypt. Soc. Parasitol. 15, 2:713-5.

Mansour, NS, Awadalla, HN, Youssef, FG, Tewfik, S, 1984: Characterization of Leishmania isolates from children with visceral infections contracted in Alexandria, Egypt. Trans. R. Soc. Trop. Med. Hyg. 78, 5:704

Michael, SA, Morsy, TA, El-Seoud, S F, Saleh, MS, 1982: Leishmaniasis antibodies in stray cats in Ismailiya Governorate, Egypt. J. Egypt. Soc. Parasitol. 12, 1:283-6.

Morsy, TA, Mandour, AM, AbdelR- 
ahman, AM, 1985: Leishmanial antibodies in stray dogs from Assiut Governorate, Egypt. J. Egypt. Soc. Parasitol. 15, 2:427-30.

Morsy, TA, Salama, MM, Abdel Hamid, MY, 1987: Detection of Leishmania antibodies in bats. J. Egypt. Soc. Parasitol. 17, 2:797-8.

Morsy, TA, 1997: Visceral leishmaniasis with special reference to Egypt (Review and Comment). J. Egypt. Soc. Parasitol. 27, 2:373-96.

Morsy, TA, Michael, SA, El Disi, A M, 1980: Cats as reservoir hosts of human parasites in Amman, Jordan. J. Egypt. Soc. Parasitol. 10, 1:5-18.

Morsy, TA, Michael, SA, Feinsod, F M, Rifaat, MA, 1983: Canine reservoir for visceral leishmaniasis in El Agamy (Alexandria) Egypt. J. Egypt. Soc. Parasitol. 13:551-5.

Morsy, TA, Schnur, LF, Feinsod, F M, Salem, AM, Wahba, MM, et al, 1987: Natural infections of Leishmania major in domestic dogs from Alexandria, Egypt. Am. J. Trop. Med. Hyg. 37, 1:49-52.

Morsy, TA, Schnur, LF, Feinsod, F M, Michael, SA, Saah, A, et al, 1988: The discovery and preliminary characterization of a novel trypanosomatid parasite from Rattus norvegicus and stray dogs from Alexandria, Egypt. Ann. Trop. Med. Parasitol. 82, 5:437-44.

Morsy, TA, Salama, MMI, Abdel Fattah, SA, 1989: On Phlebotomus langeroni in the North Coastal Zone, Egypt. J. Egypt. Soc. Parasitol. 19, 2: 759-62.

Morsy, TA, El-Missiry, AG, Kamel, AM, Fayad, ME, El-Sharkawy, IM,
1990: Distribution of Phlebotomus species in the Nile Delta, Egypt. J. Egypt. Soc. Parasitol. 20, 2:589-97.

Morsy, TA, Mangoud, AM, Aly, MA, Farrag, AM, 1992: Lymphatic leishmaniasis: An adult case without visceral involvement from Sharkia G, Egypt. J. Egypt. Soc. Parasitol. 22, 2:533-7.

Morsy ,TA, Aboul Ela, RG, Sarwat, MA, Arafa, MA, el Gozamy, BM, 1993: Some aspects of $P h$. papatasi (Scopoli) in greater Cairo, Egypt. J. Egypt. Soc. Parasitol. 23, 2: 399-416

Panayotatou, AA, 1922: Quelque cas de splenomegalie et de kala-azar autochtones chez les indigene en Egypte. Bull. Soc. Path. Exot. 15:834-53.

Rosypal, AC, Bowman, SS, Epps, S A, El Behairy, AM, Hilali, M, et al, 2013: Serological survey of dogs from Egypt for antibodies to Leishmania species. J. Parasitol. 99, 1:170-1.

Soliman, N, 1992: Sero-diagnosis of visceral leishmaniasis among primary school children in Alexandria. J. Egypt. Publ. Hlth. Assoc. 67, 3/4:491-9.

Soliman, MS, Morsy, TA, Abdel Messih, MS, el Missiry, AG, 1984: Pentostam the drug of choice in visceral leishmaniasis in Egypt. J. Egypt. Soc. Parasitol. 14, 2:311-20.

Tewfik, S, Kassem, SA, Aref, MK, Awadallah, HN, Abadir, A, 1983: A preliminary report on two cases of visceral leishmaniasis in Egypt Trans. R. Soc. Trop. Med. Hyg. 77:334-5.

Trainor, KE, Porter, BF, Logan, KS, Hoffman, RJ, Snowden, KF, 2010: Eight cases of feline cutaneous leishmaniasis in Texas. Vet. Pathol. 47, 6: 1076-81. 